\title{
Políticas públicas educacionais e o estabelecimento da Universidade Aberta do Brasil
}

\author{
Education public policies and the establishment of the Open University of \\ Brazil
}

\section{Politicas publicas y el esteblecimiento de la Universidad Abierta de Brasil}

\author{
Elcimar Malta ${ }^{2}$ \\ Karl Schurster ${ }^{3}$
}

\begin{abstract}
Resumo: Este artigo tem como objetivo o estudo das políticas relacionadas ao estabelecimento da Universidade Aberta do Brasil (UAB), como principal forma de ampliação e difusão de cursos superiores por meio da Educação a Distância no país. Utilizaremos marcos como leis e decretos pertinentes ao tema e os analisaremos de acordo com a metodologia do ciclo de política proposto por Gary Brewer e elucidado por Howlett, Ramesh e Perl. Faremos a abordagem de documentos como o Plano Nacional de Educação (PNE 2001-2010), que informa sobre o uso da Educação a Distância para o Ensino superior, que possui lacunas significativas a serem preenchidas posteriormente pelos decretos: 5.266/2005, 5.800/2006 e 9.057/2017. Como resultados, temos a reunião e discussão das principais leis e decretos que justificam o estabelecimento da UAB como política pública educacional. Concluímos que esta política iniciou um novo ciclo após o rompimento da hegemonia do Governo Federal, entre os anos de 2003 a 2016.
\end{abstract}

Palavras-chave: Políticas públicas. Educação a distância. Universidade Aberta do Brasil.

\begin{abstract}
This essay aims to study policies related to the establishment of the Open University of Brazil (UAB) as the main form of expansion and dissemination of higher education through distance in the country. We will use landmarks as laws and decrees relevant to the subject and analyze them according to the policy cycle methodology proposed by Gary Brewer and elucidated by Howlett, Ramesh and Perl. We will deal with documents such as National Education Plan (PNE 2001-2010), which informs about the use of Distance Education for Higher Education and leaves significant gaps, but it was filled by decrees 5.266/2005, 5.800/2006 and 9.057/2017. The results, there is a compilation and discussion about the main decrees and laws which justify the establishment of UAB as a education policy. That policy began a new cycle after the disruption of the hegemonic of Federal Government between the years of 2003 to 2016.
\end{abstract}

Keywords: Public policies. Distance education. Open University of Brazil.

Resumen: Este trabajo ha sido el objetivo o estudios de politica relacionados com el estabelecimiento de la Universidad Abierta de Brasil (UAB) como la principal forma de expandir y difundir la educación superior através de la educación a distancia. Usaremos marcos tales como leyes y decretos relevantes para el tema y los analizaremos de acuerdo com la metodología del ciclo de políticas propuestas por Gary Brewer e elucidado por Howlett, Ramesh y Perl. Abordaremos documentos como el Plano Nacional de Educación (PNE 20012010), que informa sobre el uso de la Educación a Distancia para la Educación Superior, por ejemplo, firmas significativas de los decretos 5.266/2005, 5.800/2006 y 9.057/2017. Como resultado, tenemos que cumplir y discutir las principales leyes y decretos que justifican el estabelecimiento de la universidad abierta del Brasil como uma politica publica educativa. Concluimos que esta politica ha empezado un nuevo ciclo después del rompimiento de la hegemonía del Gobierno Federal entre 2003 y 2016.

Palabras clave: Politicas públicas. Educación a distancia. Universidad Abierta de Brasil.

\footnotetext{
${ }^{1}$ Submetido em: 25 set. 2019 - Aceito em: 24 nov. 2019 - Publicado em: 30 set. 2020

${ }^{2}$ Universidade de Pernambuco (UPE) - E-mail: malta.elcimar@gmail.com

${ }^{3}$ Universidade de Pernambuco (UPE) - E-mail: karl.shurster@ gmail.com
} 


\section{Introdução}

Políticas públicas são ações institucionais efetuadas pelos governos, que se materializam de diferentes formas. De acordo com Howlett, Ramesh e Perl (2013, p. 6), entendemos que o agente primordial da política pública é um governo que exerce um papel especial "por força de sua capacidade de tomar decisões oficiais em nome dos cidadãos", pois, como explica Norberto Bobbio, mediante o princípio da universalidade, entendido como uma das características da tipologia moderna do poder político, "se entende a capacidade que têm os detentores do poder político, e eles sós, de tomar decisões legítimas e verdadeiramente eficazes para toda a coletividade" (BOBBIO, 1998, p. 957). Dessa forma, sempre que estivermos falando sobre políticas públicas deve-se entender que são aquelas feitas pelos governos.

As políticas podem ser consideradas como ações complexas que envolvem "numerosos atores de várias organizações [...] em diferentes níveis" (RODRIGUES, 2013, p. 70) e que possui como característica chave a materialização das medidas tomadas pelos governos. É necessário lembrar que nenhuma política é feita a partir de princípios de neutralidade, ou seja, elas são tomadas a partir do(s) ator(es) que detém/detêm o poder político.

Uma das políticas educacionais em voga é a da Universidade Aberta do Brasil (UAB), política de acesso ao ensino superior desenvolvida por meio de uma parceria entre entidades Federais, Estaduais e/ou Municipais. A UAB não é uma instituição de ensino, "porém constitui-se numa rede de instituições públicas de ensino superior articuladas para a oferta de cursos superiores" (BORGES, 2015, p. 84), na modalidade a distância. Seus objetivos são desenvolver a Educação a Distância e expandir e interiorizar a oferta de cursos superiores, sobretudo para formar professores para atuação na educação básica no Brasil.

Para que haja funcionamento da política da UAB, é necessário que diversos outros mecanismos como leis, decretos e ações das três esferas públicas ajam em consonância. Com a proposta de aprimorar o entendimento da referida política acreditamos que é necessário compreender a fundo tais mecanismos que alicerçam a UAB. Portanto, este trabalho tem como objetivo central a compreensão das diversas políticas que estruturam a UAB.

No PNE 2001-2010, estabelecido pela Lei $n^{\circ}$ 10.172, de 9 de janeiro de 2001 (BRASIL, 2001), é abordado o tema Educação a Distância e utilização das Tecnologias da Informação e Comunicação (TIC), mas não é citado diretamente seu uso para o ensino superior. Porém, é colocado como primeiro objetivo para o ensino superior, elevar a taxa bruta de matrícula para $30 \%$, das pessoas entre 18 e 24 anos, e isso pode ser utilizado como justificativa para a UAB ser instituída, posteriormente.

Os cursos de graduação promovidos pela UAB não são $100 \%$ a distância, devido a obrigatoriedade dos alunos desenvolverem algumas atividades nos polos de apoio presencial, como provas, tutorias, estágios, práticas de laboratório e defesa de trabalhos, portanto, a nomenclatura de Educação a Distância para a UAB é utilizada como critério para uma maior 
diferenciação com os cursos regulares presenciais, devido à natureza semipresencial que existe nessa política de acesso ao ensino superior.

De acordo com as ideias apresentadas, a UAB é uma manifestação material do Estado por meio da política e com isso, a Educação a Distância $(\mathrm{EaD})$ aparece como ponto central na expansão do número de vagas ofertadas no ensino superior, sobretudo para os cursos de formação de professores, com a intenção de democratizar o acesso ao mesmo.

As políticas não vão do nascimento até a morte, elas são reinventadas num processo cíclico. Existem variados modelos para análise metodológica de ciclos de política e escolhemos o modelo de Gary Brewer, elucidado por Howlett, Ramesh e Perl (2013) por tratar de forma simples e direta a análise dos pontos chave do desenvolvimento da política pública. Analisamos dentro dessa perspectiva metodológica dois dos decretos que regulamentam o Art. 80 da Lei de Diretrizes e Bases da Educação Nacional (LDB 9394/96) (BRASIL, 1996), que lança as bases do funcionamento da educação a distância no Brasil e a Política do Plano Nacional de Educação 2001-2010 (BRASIL, 2001).

Esse ciclo é composto por cinco fases: (1) Montagem da Agenda; (2) Formulação da Política; (3) Tomada de Decisão; (4) Implementação; e (5) Avaliação. Tendo em vista que o Sistema Universidade Aberta do Brasil foi estabelecido a partir de decreto, ou seja, já aparecendo no ciclo de políticas na fase da tomada de decisão, há pouco material disponível para discutirmos de forma ampliada o ciclo completo.

Em Decretos, as duas primeiras fases concernentes ao ciclo não necessariamente se tornam acessíveis ao público, como normalmente são feitas com as leis, em que há a publicação desde a exposição de motivos para a criação de uma nova lei, seu texto provisório, debate e votação nas casas legislativas do Brasil. Buscamos, portanto, a partir da análise do Plano Nacional de Educação (BRASIL, 2001) reconstituir a primeira fase do ciclo, uma vez que no momento do decreto de criação da UAB, o PNE vigente era o referido documento.

\section{Instituição e expansão da política pública da Universidade Aberta do Brasil}

A expansão dos cursos a distância por intermédio das Instituições de Ensino Superior (IES) públicas é regida pela Universidade Aberta do Brasil (UAB), criada pelo Decreto $\mathrm{n}^{\circ}$ 5.800 , de 8 de junho de 2006, e que tem por objetivos: desenvolver a EaD, expandir e interiorizar a oferta de cursos superiores no Brasil (BRASIL, 2006). A UAB funciona a partir de uma parceria entre União, Estados e Municípios, em que há repartição de atribuições, tais como fornecimento de verbas, contratação de professores, coordenadores, tutores presenciais e a distância, manutenção dos polos presenciais, fornecimento de pessoal para apoio técnico etc. Com esse decreto, a $\mathrm{EaD}$ foi instituída como política para o incentivo ao desenvolvimento da educação superior, sobretudo, no interior do país, para formar profissionais da educação básica (BRASIL, 2006).

Para fazer a política pública é necessário identificar um problema, buscar uma solução e aplicá-la, mesmo que todo esse percurso seja permeado de imperfeições. No caso da UAB, um dos problemas identificados foi a falta de acesso ao ensino superior por habitantes em 
grande parte do interior do país. Existem universidades estaduais e federais atuantes no interior do país, porém, a demanda é maior do que a oferta de vagas e, além disso, tais IES não conseguem atender presencialmente locais com muita procura por cursos de graduação. Identificado o problema de oferta de vagas, a política da UAB foi instituída como uma das soluções para incrementar o número de ingressantes nas IES públicas pelo país, principalmente no interior com ênfase nas licenciaturas. A partir disso, apresentamos o segundo cenário da educação superior promovida pela Universidade de Pernambuco (UPE) com o acréscimo da EaD.

O funcionamento da UAB se estabelece a partir da colaboração entre Agentes Federais, Estados e Municípios. Cabe ao Governo Federal dar as diretrizes de funcionamento dos cursos, como carga horária de disciplinas obrigatórias e optativas, assim como atividades complementares. Também é de competência da União fazer o pagamento de alguns agentes (esse que é feito por meio de um sistema de bolsas), como tutores, coordenadores de curso e professores. Já aos estados e/ou aos municípios cabe fornecer, sobretudo, o polo de apoio presencial, que é uma "unidade operacional para o desenvolvimento descentralizado de atividades pedagógicas e administrativas relativas aos cursos e programas ofertados a distância pelas instituições públicas de ensino superior" (BRASIL, 2006).

Os polos são espaços onde se efetuam as atividades presenciais, "como tutoria, avaliações, estágios, práticas profissionais e de laboratório, defesa de trabalhos" (BRASIL, 2017) etc. O polo presencial também deve "dispor de infraestrutura e recursos humanos adequados" (BRASIL, 2006), tanto para atender as atividades citadas no início deste parágrafo, quanto para ser um ambiente de estudo para os estudantes que desejarem estar num espaço que favoreça seus estudos. É importante que o polo de apoio possua, por exemplo, biblioteca, laboratório de informática e a eventual presença de um tutor de seu curso para dar suporte técnico e acadêmico para os estudantes.

Entidades Estaduais e Municipais que se interessarem pela manutenção de um polo de apoio presencial deverão atender algumas exigências do Ministério da Educação, esse, que "firmará acordos de cooperação técnica ou convênios com os entes federativos [...] mediante edital" (BRASIL, 2006). Dessa forma, identificamos os meios cooperativos para o funcionamento dos cursos da UAB, em que as IES participam com o fornecimento e regulamentação dos cursos; estados e municípios mediante contrapartida vista em edital oferecem o espaço físico para atividades que necessariamente devem ser feitas presencialmente e a União, por meio de seus vários órgãos, fornece verbas para contratação de pessoal mediante sistema de bolsas.

Como observado, a interiorização do ensino superior por meio da $\mathrm{EaD}$ foi uma forma buscada pelo governo de democratizar o acesso às IES públicas, por meio da UAB e seus convênios com as universidades e institutos federais. Acerca desse processo, Falcão e Schurster (2016, p. 12) afirmam que "democratização do ensino não é apenas acesso a sala de aula", mesmo que virtual. Há uma série de fatores que levam esse processo a se concretizar. De acordo com Ana Cavalcanti (2016, p. 20), o "princípio democrático presume condição de direito na busca por uma igualdade de condições". 
Portanto, o simples fato de abrir uma determinada quantidade de vagas nas universidades não garante por si só que as pessoas que as preencherão terão as mesmas condições de aproveitamento; para isso, é necessário que haja ação de outras políticas públicas no sentido de promover a democratização. Assim, "falar em democratização implica assegurar o direito a todos de educação pública de qualidade, com oportunidades iguais de formação" (ANDRADE, 2015, p. 241).

A criação da Universidade Aberta do Brasil segue uma lógica de EaD baseada em modelos já existentes em países da Europa, desde a década de 1970, e seu estabelecimento como política educacional só foi possível graças ao Art. n 80 da LDB 9394/96 (BRASIL, 1996), que versa sobre o incentivo e desenvolvimento da educação brasileira em todos os níveis de ensino por meio da modalidade a distância. Posteriormente, foi necessário um decreto para regulamentar o referido artigo da LDB, pois o mesmo era limitado a apresentar a $\mathrm{EaD}$ como uma possibilidade de viabilização do processo de ensino-aprendizagem.

\section{Resultados do ciclo de política de regulamentação da UAB}

Há duas lacunas presentes no PNE 2001-2010 (BRASIL, 2001) interessantes ao nosso estudo. A primeira é referente à regulação das instituições provedoras em Educação a Distância, pois, como é dito no documento, "à União cabe o credenciamento das instituições autorizadas a oferecer cursos de educação a distância, assim como o estabelecimento dos requisitos para a realização de exames e o registro de diplomas" (BRASIL, 2001). É estabelecido na lei que compete à União as atividades supracitadas, porém não informa como deve ser essa prática.

A segunda lacuna é em relação ao sistema em que será desenvolvido a Educação a Distância, no Brasil, e essa abertura é uma justificativa para a criação, posterior, da UAB. Essas lacunas foram importantes para o estabelecimento das políticas que regulam a UAB em si e algumas práticas auxiliares, como o uso das Tecnologias de Informação e Comunicação (TIC), avaliações presenciais, emissão de diplomas, credenciamento e recredenciamento de instituições que oferecem cursos a distância.

No ano de 1998, com o Decreto $n^{\circ}$ 2.494, de 10 de fevereiro (BRASIL, 1998), estabeleceu-se a primeira regulamentação do Art. 80i da LDB 9394/96, sendo este revogado no ano de 2005 em favor do Decreto $\mathrm{n}^{\circ}$ 5.622, assinado em 19 de dezembro. Este, por sua vez, foi revogado em 25 de maio de 2017, pelo Decreto ${ }^{\circ} 9.057$. No espectro da mudança de regulação da $\mathrm{EaD}$, é possível ver a manifestação do ciclo de política proposto por Gary Brewer, em que ele "Introduziu a noção do processo da política pública como um ciclo em constante movimento. Reconheceu também que a maior parte das políticas não tem um ciclo de vida fixo, que vai do nascimento à morte" (HOWLETT; RAMESH; PERL, 2013, p. 14). Para fins de análise, exploramos apenas os dois últimos decretos, pois estabelecem que a educação a distância deve ser efetivada por meio das Tecnologias da Informação e Comunicação. 
Por meio do Decreto ${ }^{\circ}$ 5.266/2005 houve a regulamentação no Art. 80, da Lei de Diretrizes e Bases, que propõe a Educação a Distância como possibilidade de ensino em todos os níveis educacionais. Essa política, do Ministério da Educação serviu como base para o estabelecimento do Decreto ${ }^{\circ} 5.800 / 2006$, que institui o Sistema Universidade Aberta do Brasil, ou seja, o primeiro decreto mencionado surgiu como o preenchimento da primeira lacuna ao PNE 2001-2010 e o segundo decreto preenche a segunda lacuna citada anteriormente.

O que concerne à primeira etapa do ciclo de políticas, está intrinsecamente ligado às demandas propostas dentro da esfera governamental e, por esse motivo, o estabelecimento de decretos aparece como propostas mais eficientes e diretas na implantação de uma política pública. Tanto a segunda parte (Formulação da Política) quanto a terceira (Tomada de Decisão), do ciclo de políticas escolhido para análise, são comprometidos, devido à forma como as políticas foram institucionalizadas, ou seja, por meio de decreto. Pelo fato de termos acesso apenas ao decreto em si e à publicação feita em Diário Oficial da União, que possuem o mesmo conteúdo, não há como aprofundarmos a análise em relação à formulação da política. Já em relação à tomada de decisão, terceira fase, o Decreto pode ser entendido como a tomada de decisão feita pelo poder executivo mediada pelo Ministério da Educação.

$\mathrm{Na}$ quarta parte do ciclo, temos a implementação, que são as formas como as políticas serão efetivamente aplicadas. Dentro das teorias ligadas a essa prática, a UAB é um tipo de política top-down, ou seja, ela é estabelecida de "cima para baixo", da esfera Estatal para o público. O quinto ponto, Avaliação, se dá dentro do universo da política, assim, ela está sujeita a escolha e mudança de método de acordo com o grupo que está no poder. Portanto, devido ao fato de a UAB ser no seu cerne uma política de acesso, os dados que prevalecerão, na análise da eficácia do sistema para os proponentes da política, serão os numéricos, priorizando a capacidade do sistema em ofertar e preencher vagas no ensino superior.

Ao analisarmos as Sinopses da Educação Superior no Brasil, documentos disponíveis no site do Instituto Nacional de Estudos e Pesquisas Educacionais Anísio Teixeira (INEP), identificamos a progressão dos dados em relação ao acesso promovido pela UAB, desde o ano de 2009, primeiro ano em que a Educação a Distância aparece no Censo da Educação Superior e, por conseguinte, nas sinopses.

Foram analisados três pontos: (1) Número de ingressantes; (2) Total de matriculados; e (3) Concluintes. Com esses dados, observamos que a política de acesso se mantém regular durante o período de amostragem dos dados, que vai de 2009 a 2017. Apenas no ano de 2009, há uma grande disparidade em relação aos outros anos, que não é explicado no documento. Somos levados a acreditar que tal disparidade tenha ocorrido por conta do início da implementação da política, em que o incentivo financeiro foi bastante alto. Consolidamos esses dados na Tabela 1, para facilitar a visualização da análise. 
Tabela 1. Desenvolvimento da UAB em todos os Estados da Federação (2009-2017)

\begin{tabular}{cccc}
\hline Ano & $\mathbf{N}^{\mathbf{0}}$ de ingressos & Total de Matriculados & Concluintes \\
\hline 2009 & 332.469 & 838.125 & 132.269 \\
2010 & 40.174 & 181.602 & 12.190 \\
2011 & 34.045 & 177.924 & 23.699 \\
2012 & 48.527 & 181.624 & 35.152 \\
2013 & 36.906 & 154.553 & 23.017 \\
2014 & 43.915 & 139.373 & 16.051 \\
2015 & 30.323 & 128.393 & 15.700 \\
2016 & 24.490 & 122.601 & 15.303 \\
2017 & 86.965 & 165.572 & 13.732 \\
\hline
\end{tabular}

Fonte: INEP/MEC (BRASIL, 2018).

De acordo com a Tabela 1, é notório o número de ingressantes na $\mathrm{EaD}$ em pouco tempo de estabelecida. No ano de 2016, se observa o menor número de ingressantes e, o de 2009 o de maior, 24.490 e 332.469 pessoas, respectivamente. Entre os anos de 2010 e 2016 se vê uma constância nesse ponto e uma variação que chega a cerca de 24 mil pessoas entre a menor e a maior taxa de ingresso, o que para um sistema que tem por base financiamento externo às instituições que ofertam os cursos, é possível considerar que há regularidade do ingresso. Em relação aos outros dois pontos, verifica-se algo semelhante em suas devidas proporções.

Levando em consideração que dentro do número total de matriculados está a maior parte dos ingressantes e dos concluintes do mesmo ano, com a exceção do ano de 2009, a evasão foi algo bastante controlada. Nesse ano, houve a saída de pouco mais de 132 mil pessoas do sistema devido à conclusão do curso, porém, com os seus mais de 838 mil matriculados, a situação relativa à matrícula deveria estar na faixa dos 700 mil. Entretanto, o número total de matrículas entre alunos novatos e veteranos é de 181.602 pessoas, o que mostra uma evasão de mais de 500 mil alunos.

Nos anos seguintes, de acordo com os dados fornecidos pelo INEP, essa situação se manteve constante, tendo em vista que, em 2010, por exemplo, 12.190 pessoas concluíram seus cursos, deixando o saldo de matriculados em 169.412 mil pessoas. No ano de 2011, houve 34.045 estudantes ingressantes, o que deixaria um saldo de 203.457 pessoas, entretanto, o número de matriculados foi de 177.964, ou seja, a evasão (entre desistência do curso ou não efetuação da matrícula) foi de 25.533 .

Ao estabelecermos a taxa de evasão nesses moldes, temos a tabela 2: 
Tabela 2. Evasão na UAB em todos os Estados da Federação (2009-2017)

\begin{tabular}{cc}
\hline Ano & Número de Evasão \\
\hline $2009-2010$ & 564.428 \\
$2010-2011$ & 25.533 \\
$2011-2012$ & 21.128 \\
$2012-2013$ & 28.825 \\
$2013-2014$ & 6.087 \\
$2014-2015$ & 25.252 \\
$2015-2016$ & 14.582 \\
$2016-2017$ & 28.691 \\
\hline
\end{tabular}

Fonte: INEP/MEC (BRASIL, 2018).

Baseando-se nos dados oficiais do INEP, a política da Universidade Aberta do Brasil pode ser considerada como efetiva no que diz respeito ao acesso ao ensino superior. Apesar de em alguns anos a taxa de ingresso ser semelhante ao da evasão, há manutenção e constância tanto no número de matriculados quanto de concluintes, mostrando que a política em questão, ainda na fase inicial de desenvolvimento, por ter pouco mais de 10 anos de estabelecida por decreto, consegue cumprir com um dos seus principais objetivos.

A partir da perspectiva do ciclo de políticas, após a avaliação há a possibilidade de um retorno para a primeira fase, ou seja, uma nova montagem de agenda, que pode ser tanto uma continuidade da agenda que estabeleceu inicialmente a política quanto uma ruptura, pois as políticas públicas são efetivadas, em geral, pelos agentes governamentais e nunca se baseiam em pressupostos de neutralidade, então, a partir de uma mudança na base dos governos é natural que haja modificações nas formas de condução da burocracia estatal. No ano de 2016, houve significativas mudanças na base do governo federal e muitas políticas foram alteradas para o alinhamento com as agendas dos partidos que compunham tal base. $\mathrm{O}$ decreto que regulamenta o Art. 80 da LDB foi alterado, dando-nos a possibilidade de analisar o reinício no ciclo de política da UAB.

\section{Análise dos Decretos sobre o uso da Educação a Distância}

Para fins de facilitar o entendimento e deixar o texto mais fluido, chamaremos o Decreto $n^{\circ}$ 5.622, de 19 de dezembro de 2005 de Primeira Versão e o Decreto $n^{\circ}$ 9.057, de 25 de maio de 2017 de Segunda Versão, da regulamentação do Artigo n 80 da Lei $n^{\circ}$ 9.394/96. Analisaremos comparativamente os dois textos, trazendo dados quantitativos e em maior parte, qualitativos. Para delimitar o escopo da análise, será feita uma comparação entre os seguintes pontos dos Decretos: Oferta de cursos superiores e credenciamento dos cursos, utilização das Tecnologias da Informação e Comunicação e Atividades presenciais obrigatórias.

Cada Decreto possui um capítulo reservado para sistematizar como será a oferta de cursos superiores pela EaD. A Primeira Versão conta com apenas 4 artigos e 5 incisos; já a 
Segunda Versão conta com 9 artigos e 10 incisos. Nesse caso, é possível visualizar que a segunda versão possui mais detalhes que a antecessora.

No Art. 20 da Primeira Versão, que trata sobre a prerrogativa de abertura de cursos superiores, diz que somente "as instituições que detêm prerrogativa de autonomia universitária credenciadas para oferta de educação superior" (BRASIL, 2005), poderão abrir ou fechar cursos de graduação e pós-graduação na modalidade a distância. Na Segunda Versão do documento não há menção a respeito do grau de autonomia que a instituição necessita para abrir um curso superior a distância, porém ressalta que as IES públicas têm reconhecimento automático para abertura de cursos e que as instituições privadas devem solicitar autorização junto ao MEC.

$\mathrm{Na}$ Primeira Versão consta que instituições sem autonomia universitária devem solicitar "junto ao órgão competente do respectivo sistema de ensino, autorização para abertura de cursos e programas" (BRASIL, 2005) em EaD, ou seja, anteriormente, havia um caminho mais longo a ser tomado para poder ofertar um curso superior a distância, visto que a partir da Segunda Versão as instituições podem solicitar diretamente ao MEC seu credenciamento para oferta de cursos.

Uma forma de deixarmos explícita a diferença existente entre os dois Decretos regulamentadores e que pode comprometer a qualidade de cursos de $\mathrm{EaD}$ refere-se ao credenciamento da instituição junto ao Ministério da Educação. Na Primeira Versão, é dito que "o pedido de credenciamento da instituição para educação a distância deve vir acompanhado de pedido de autorização de pelo menos um curso na modalidade" (BRASIL, 2005), já a Segunda Versão destaca apenas que "as instituições de ensino superior privadas deverão solicitar credenciamento para a oferta de cursos superiores na modalidade a distância ao Ministério da Educação" (BRASIL, 2017), sem mencionar a necessidade de apresentação de uma proposta de curso.

A Primeira Versão dispõe de um capítulo para tratar do assunto em questão, em que é exposto todas as possibilidades de credenciamento, recredenciamento e descredenciamento em todos os níveis educacionais, enquanto na Segunda Versão, são dedicados poucos artigos e parágrafos que tratam desse tema e se encontram diluídos pelo Decreto inteiro. Assim, percebemos indícios de fraqueza e abertura demasiada da Segunda Versão em relação à Primeira, principalmente no que diz respeito ao credenciamento dos cursos.

Há um ponto que podemos observar melhoria, é em relação ao credenciamento das IES públicas. De acordo com a Segunda Versão, a IES pública que desejar ofertar algum curso na modalidade a distância terá seu credenciamento feito de forma automática, uma vez que em seu Art. 12, destaca que "as instituições de ensino superior públicas dos sistemas federal, estaduais e distrital ainda não credenciadas para a oferta de cursos superiores na modalidade a distância ficam automaticamente credenciadas pelo prazo de cinco anos" (BRASIL, 2017).

Em ambas versões do Decreto, a Educação a Distância é caracterizada pelo uso das TIC no processo educacional, utilizando-a como meio de comunicação e interação entre professores, tutores, estudantes, "desenvolvendo atividades educativas em lugares ou tempos 
diversos" (BRASIL, 2005). Ambas definições estão postas nos Art. 1. A Segunda Versão do documento é mais completa, pois além da mediação didático-pedagógica ser feita por meio de ferramentas das TIC, haverá trabalho efetuado por "pessoal qualificado, com políticas de acesso, com acompanhamento e avaliação compatíveis" (BRASIL, 2017). Caracterizamos a definição da Segunda Versão como mais completa por contemplar em seu texto a necessidade de:

a) Haver pessoal qualificado. Para executar as atividades de tutor e professor na EaD é preciso ter alguma formação na área, pois o Ambiente Virtual de Aprendizagem se torna a sala de aula, entretanto, não há a mesma dinâmica dos cursos presenciais e, portanto, as atividades propostas a distância não podem ser iguais às do ensino regular presencial.

b) Avaliação compatível. Já que o ambiente principal de aprendizado deve ser pensado de forma diferente da sala de aula convencional, a avaliação deve se dar da mesma forma. As avaliações precisam ser elaboradas para estimular os alunos a se debruçarem sobre os conhecimentos e não apenas reproduzirem técnicas de respostas aos testes de múltipla escolha, por exemplo. As avaliações também necessitam ser pensadas de acordo com o ambiente virtual que será utilizado, pois os diversos sistemas possuem variados modos de avaliação do aprendizado.

A avaliação nos cursos presenciais, normalmente, se dá por meio de provas ou trabalhos, que compõem $100 \%$ da nota de cada unidade. Geralmente, nos cursos a distância se faz (ou se deve fazer) de maneira diferente. A nota de cada unidade deve ser dividida entre três ou mais atividades, desde que a prova presencial tenha peso maior que $50 \%$ da nota final.

$\mathrm{Na}$ Primeira Versão é dito que "as atividades presenciais obrigatórias, compreendendo avaliação, estágios, defesa de trabalhos ou prática em laboratório" (BRASIL, 2005), devem ser feitas nos polos presenciais. Na Segunda Versão, há a permanência desses mesmos itens, entretanto, não há menção em relação à obrigatoriedade, pois, deixa muito vago, ou subentendido que essas atividades não são facultativas de serem executadas nos polos. O Art. 4 versa o seguinte:

As atividades presenciais como tutorias, avaliações, estágios, práticas profissionais e de laboratório e de defesa de trabalhos [...] serão realizadas na sede da instituição de ensino (no caso do ensino privado), nos polos de educação a distância ou em ambiente profissional (BRASIL, 2017).

Na Segunda Versão não há indicativo de que as atividades supracitadas são de caráter obrigatório e o deslocamento para a execução de atividades nos polos busca inviabilizar e/ou dificultar o acesso aos cursos da $\mathrm{UAB}$, por pessoas que residam nas capitais, o que é uma barreira positiva, pois um dos objetivos principais da política pública em questão é aumentar o acesso ao ensino superior para pessoas que residam no interior do país. Devido a isso, há a possibilidade de desvirtuamento do sentido original da política da UAB, que é interiorizar os cursos de licenciaturas, a fim de elevar a qualidade da educação básica nos mais variados municípios da federação. Constatamos que há na Segunda Versão uma grande brecha em relação ao controle das atividades presenciais obrigatórias, por parte dos estudantes das graduações da UAB. 


\section{Considerações finais}

Foram apresentadas definições do que são políticas públicas e formas de como estas se materializam na sociedade. No caso estudado, a política é a do estabelecimento da Universidade Aberta do Brasil e sua manifestação material foi vinculada ao caso da Universidade de Pernambuco. A possibilidade de ampliação do escopo de atuação das universidades públicas tornou-se uma realidade por meio do uso das Tecnologias da Informação e Comunicação.

Sabemos que o simples uso das Tecnologias da Informação e Comunicação para fins educacionais não resolve problemas de permanência de estudantes nos diversos cursos superiores ofertados em parceria com a Universidade Aberta do Brasil. O uso da EaD por Instituições de Ensino Superior públicas, portanto, não pode ser encarada como a solução dos problemas, mas como uma alternativa de abrangência da oferta do ensino para regiões do país em que o ensino presencial, devido às suas limitações físicas, não consegue atender.

Entendemos pelo uso da metodologia de análise do ciclo de políticas que essas não nascem e morrem, mas que continuamente são reinventadas e ressignificadas a partir de lacunas deixadas por legislações e por necessidades diversas da expansão da atuação do Estado. Como vimos, a primeira vez em que a educação a distância foi mencionada em política pública foi na Lei de Diretrizes e Bases da Educação Nacional, em 1996, e a partir, especificamente, do Art. $n^{\circ} 80$ pôde se desenvolver decretos e outras leis que impulsionaram o estabelecimento da modalidade a distância como forma factual de promoção da educação em todos os níveis de escolaridade.

A política da Universidade Aberta do Brasil surgiu para concluir as projeções e pretensões estabelecidas no PNE 2001-2010, que possuía, conforme mencionado anteriormente, duas lacunas identificadas na seção destinada à educação a distância, uma relacionada com a regulação das entidades de ensino provedoras de cursos e outra relativa ao sistema que desenvolveria a EaD no âmbito público.

A partir do Decreto $\mathrm{n}^{\circ} 5.800 / 2006$ pudemos analisar e discutir suas manifestações e desdobramentos, sobretudo, no caso específico da Universidade de Pernambuco, que possui atuação direta da UAB, com a promoção de cinco cursos de graduação a distância e do uso das ferramentas da UAB para a expansão do uso das TIC no ensino presencial.

Vimos, neste texto, como as políticas públicas se estabelecem e modificam-se de acordo com as necessidades e agendas dos detentores do poder. $\mathrm{Na}$ análise metodológica do ciclo de políticas, observamos dentro da política do PNE 2001-2010 duas lacunas que puderam ser utilizadas como justificativas para a criação da Universidade Aberta do Brasil. Sem a regulamentação do Art. 80 da LDB, não seria possível criar uma política como a UAB, ou seja, era necessário em primeiro lugar regulamentar as formas e meios da educação a distância para, posteriormente, instituir o sistema que coordenaria a expansão do ensino superior pela Educação a Distância.

As análises dos dados das sinopses da educação superior são os melhores indicativos que a UAB como política de acesso está demonstrando sucesso. Os indicadores de alto 
volume de ingressantes no início da política são sintomáticos do investimento aplicado para que a política tivesse adesão por parte das universidades e estudantes. Posteriormente, há uma baixa no número de ingressos e um aumento na evasão, que podem ser explicados por falta de adaptação à modalidade de ensino em questão, devido à inúmeros fatores como falta de acesso à internet e aparelhos como computadores e tablets, falta de organização pessoal para os estudos em função, por exemplo, da carência de um mentor que disciplina e cobra atividades, falta de diálogo contínuo e estabelecimento de confiança com colegas e professores. Após momentos de alta evasão, houve regularização da oferta e ingresso versus evasão. Assim, como política de acesso a UAB se mostra efetiva, pois mantém a regularidade.

Outras políticas correlacionadas para o estabelecimento da UAB são os decretos que regulamentam o Art. 80 da $\mathrm{LDB}$, que versa sobre a possibilidade do uso da Educação a Distância em todos os níveis de ensino no Brasil. A Primeira Versão do Decreto, como vimos, foi assinada no ano de 2005 e a Segunda Versão em 2017, revogando a primeira. Vimos, também, que houve algumas continuidades e rupturas, em que avaliamos qualitativamente algumas das propostas dos dois Decretos comparando-as e identificando alguns avanços e retrocessos.

Na Segunda Versão há um avanço em relação ao uso das TIC, pois sua definição é mais completa e contempla a necessidade de haver pessoal qualificado para executar as atividades de tutor e professor, ou seja, a necessidade desses atores possuírem formação específica para desempenhar o papel docente em Ambientes Virtuais de Aprendizagem. Outros pontos que consideramos como avanço, da Segunda Versão em relação à Primeira, são as políticas de acesso e avaliação compatível. A UAB em si, é uma política de acesso, porém, é mencionado que entidades estaduais e municipais podem tanto cobrar quanto desenvolver políticas auxiliares para incrementar o acesso dos alunos ao sistema UAB. Em relação ao segundo ponto, ao considerarmos a $\mathrm{EaD}$ uma modalidade que necessita de metodologia específica para ser desenvolvida, a avaliação também deve ser pensada de acordo.

Em relação ao credenciamento de cursos e instituições, na Primeira Versão, é posto que apenas as universidades podem abrir ou fechar cursos de graduação a distância. Já na Segunda Versão, não há menção quanto ao grau de autonomia que a IES deve ter, ou seja, deixa aberta a possibilidade para que faculdades e centros universitários possam criar cursos a distância, sem necessidade de parceria ou filiação com uma universidade. Na Segunda Versão, um avanço observado é que a IES pública tem de forma automática o reconhecimento do curso.

Na Primeira Versão, o credenciamento é possível apenas quando já existe uma proposta de curso autorizada para abertura. Na Segunda, é colocado que as instituições devem solicitar ao MEC o credenciamento, mas não menciona a necessidade de apresentação e/ou autorização de uma proposta de curso. Em outras palavras, instituições de ensino superior, sobretudo, as privadas, podem solicitar o credenciamento de cursos a distância sem ao menos terem um projeto de curso apresentado. Vemos isso como um retrocesso. 
Ainda sobre o credenciamento, há na Primeira Versão um capítulo inteiro disposto para as questões de credenciamento, descredenciamento e recredenciamento de cursos e instituições, enquanto na Segunda Versão esses pontos estão diluídos e são mencionados ao longo do texto sem nenhuma ênfase. Vemos isso como um retrocesso, pois indica uma abertura em demasia dos requisitos mínimos para o estabelecimento de cursos a distância, favorecendo a criação de cursos superiores em quaisquer instituições, sem controle do Estado.

\section{Referências}

ANDRADE, Maria Edgleuma de. Interiorização da educação superior: demandas de democratização e parceria com o poder público municipal. Holos, Natal, v. 2, p. 235-249, abr. 2015. https://doi.org/10.15628/holos.2015.2192.

BOBBIO, Norberto. Política. In: BOBBIO, Norberto; MATTEUCI, Nicola; PASQUINO, Gianfranco (org.). Dicionário de política. Tradução de Carmen C. Varriale et al. 11. ed. Brasília: UnB, 1998. p. 954-961.

BORGES, Felipe Augusto Fernandes. A EaD no Brasil e o processo de democratização do acesso ao ensino superior: diálogos possíveis. Ead em foco, Rio de Janeiro, v. 5, n. 3, p. 75 94, 2015. https://doi.org/10.18264/eadf.v5i3.283.

BRASIL. Decreto n. 2.494, de 10 de fevereiro de 1998. Regulamenta o art. 80 da Lei n. 9.394, de 20 de dezembro de 1996, e dá outras providências. Diário Oficial da União, Brasília, DF, 11 fev. 1998.

BRASIL. Decreto n. 5.622, de 19 de dezembro de 2005. Regulamenta o art. 80 da Lei n. 9.394, de 20 de dezembro de 1996, que estabelece as diretrizes e bases da educação nacional. Diário Oficial da União, Brasília, DF, 20 dez. 2005.

BRASIL. Decreto n. 5.800, de 8 de junho de 2006. Dispõe sobre o Sistema Universidade Aberta do Brasil - UAB. Diário Oficial da União, Brasília, DF, 9 jun. 2006.

BRASIL. Decreto n. 9.057, de 25 de maio de 2017. Regulamenta o art. 80 da Lei n. 9.394, de 20 de dezembro de 1996, que estabelece as diretrizes e bases da educação nacional. Diário Oficial da União, Brasília, DF, 26 maio 2017.

BRASIL. Instituto Nacional de Estudos e Pesquisas Educacionais Anísio Teixeira (Inep). Sinopses Estatísticas da Educação Superior - Graduação. Brasília: INEP/MEC, 2018. Disponível em: http://inep.gov.br/sinopses-estatisticas-da-educacao-superior. Acesso em: 20 nov. 2018.

BRASIL. Lei n. 10.172, de 09 de janeiro de 2001. Aprova o Plano Nacional de Educação e dá outras providências. Diário Oficial da União, Brasília, DF, 10 jan. 2001.

BRASIL. Lei n. 9.394, de 20 de dezembro de 1996. Estabelece as diretrizes e bases da educação nacional. Diário Oficial da União, Brasília, DF, 23 dez. 1996. 
CAVALCANTI, Ana Claudia Dantas. Políticas públicas: controle e qualidade. In: FALCÃO, Pedro Henrique de Barros; SCHURSTER, Karl (org.). Educação, política e outras

histórias. 1 ed. Rio de Janeiro: Autografia; Recife: Edupe, 2016.

FALCÃO, Pedro Henrique de Barros; SCHURSTER, Karl (org.). Educação, política e outras histórias. 1 ed. Rio de Janeiro: Autografia; Recife: Edupe, 2016.

HOWLETT, Michael; RAMESH, Mohan; PERL, Anthony. Política pública: seus ciclos e subsistemas: uma abordagem integral. Rio de Janeiro: Elsevier, 2013.

RODRIGUES, Luiz Alberto Ribeiro. Políticas de gestão escolar: uma análise do plano de desenvolvimento da escola na região da Mata Norte de Pernambuco (1999-2007). Recife: Edupe, 2013.

\section{Notas}

\footnotetext{
i “Art. 80. O Poder Público incentivará o desenvolvimento e a veiculação de programas de ensino a distância, em todos os níveis e modalidades de ensino, e de educação continuada. § $1^{\circ}$ A educação a distância, organizada com abertura e regime especiais, será oferecida por instituições especificamente credenciadas pela União. $\S 2^{\circ} \mathrm{A}$ União regulamentará os requisitos para a realização de exames e registro de diploma relativos a cursos de educação a distância. $\S 3^{\circ}$ As normas para produção, controle e avaliação de programas de educação a distância e a autorização para sua implementação, caberão aos respectivos sistemas de ensino, podendo haver cooperação e integração entre os diferentes sistemas" (BRASIL, 1996).
} 